\title{
Corporate Motivation to Risk Prevention: Applied Exploratory Analysis in Construction Sector in Catalonia
}

\author{
Fernando Terrés, ${ }^{1}$ Emilio Castejón, ${ }^{2}$ and Pedro R. Mondelo ${ }^{1}$ \\ 1 Universitat Politècnica de Catalunya, Barcelona (Spain) \\ 2 Centro Nacional de Condiciones de Trabajo, Barcelona (Spain)
}

\begin{abstract}
In this article, we have undertaken an exploratory analysis of the extrinsic and intrinsic factors affecting an employer's safety motivation in the construction industry, and their correlation with firm size, management level, and perceived risk. We have employed a model based on previous research by Michael Wright for the Health and Safety Executive (UK). Methods: A sample of managers from 198 construction firms in Catalonia (Spain) were interviewed collecting relevant data. The exploratory factor analysis of this data detected two factors: extrinsic (prosecution, inspection, external pressure) and intrinsic (legal, responsibility, internal involvement). Confirmatory factor analysis did not rule out the presence of extrinsic and intrinsic factors (Wright), and the analysis with covariates (MIMIC model) showed significant positive relationships between extrinsic factors, management level, and perceived risk. It also showed a significant positive relationship between intrinsic factors and firm size. Conclusion: The aim of this study was to make a preliminary diagnostic of an employer's safety motivation. Our findings indicate that it is possible to develop external motivators (advice from inspection bodies, union activities, publicity of prosecution records, etc.) that are addressed to top managers and to firms more exposed to risk. We have also found that it is possible to develop internal motivators by introducing experience modification ratings, social accounting, advertising in the mass media, and promotion campaigns, particularly among bigger firms. Our findings will be useful to government agencies, company managers, and consultants and may be adapted for use in motivating midlevel staff to adopt participatory intervention programs. $\odot 2011$ Wiley Periodicals, Inc.
\end{abstract}

\section{INTRODUCTION}

Article 5 of Council Directive 89/391/EEC on the introduction of measures to encourage improvements in the safety and health of workers at work states that the employer must ensure the health and safety of workers

Correspondence to: Fernando Terrés. Department of Management, Universitat Politècnica de Catalunya (Barcelona Tech), EPSEIB, Diagonal, 647-10. 08028 Barcelona (Spain) e-mail: fernando.terres@upc.edu

Received: 25 January 2010; revised 21 March 2011; accepted 21 March 2011

View this article online at wileyonlinelibrary.com/journal/hfm DOI: $10.1002 / \mathrm{hfm} .20328$ in all aspects of work. Therefore, business owners and managers must be involved in the design and application of preventive actions-a requirement that seems to be (at least from a media standpoint) as difficult for companies at the beginning of the 21st century as it was for companies a century earlier. Accounts by Barstow and Lowell for the New York Times (The Pulitzer Prizes, 2004) reveal the same corporate disinterest in worker health and safety that Taylor and Fayol observed at the beginning of the 20th century.

It is likely that this situation is the result of improvements over the past century in physical conditions (machinery and facilities), changes in how work is organized (Robbins, 2004), or the greater importance of the service sector relative to the primary and industrial 
sectors. But motivation as a factor in prevention does not appear in mainstream research on preventive management (Shannon, Mayr, \& Haines, 1997; Shannon, Robson, \& Sale, 2001; Zohar, 2002), although from a legal, scientific, and practical standpoint (spurred by social agents) emphasis is placed on the need for a preventive culture based on corporate management's motivation and commitment to integrating risk prevention into overall corporate policymaking.

Many studies deal with risk prevention from a legal standpoint (Viscusi, 1986; M. Wright, 1998), from an economic standpoint (Bird \& Germain, 1986; Dorman, 2000; Gil Fisa \& Pujol Senovilla, 2000), and from an organizational standpoint (Hale, 2003; Hofmann \& Morgeson, 1999; Perrow, 1967; Reason, 1997; Terrés de Ercilla, Mondelo, Álvarez Casado, \& Talavera Pedrol, 2002; Zohar, 2002). Few studies, however (Smallman, 2001), analyze in a comprehensive manner factors motivating business owners and managers to adopt risk prevention measures.

In the scientific literature, safety motivation has been partially studied by Hofmann, Jacobs, and Landy (1995), by Smallman (2001), and by Rundmo and Hale (2003). Hofmann and Smallman's works are largely a synthesis of the previous literature to date.

However, Rundmo and Hale employed a scientific approach based on psychological theories of reasoned and planned action and behavior (Ajzen, 1991; Ajzen \& Fishbein, 1980; Fishbein \& Ajzen, 1975), using a structural equation model applied to a sample group of 210 managers from the company Norsk Hydro to analyze the relationship between attitudes and intentions of behavior toward safety and its relationship to self-declared behavior. The approach used by the authors is supported by the theory, but to be useful, it is important that the constructs (multidimensional in character) are homogeneous within the unit of analysis. This is possible when the managers are from the same company but is difficult to justify when the contexts are heterogeneous (Wallace \& Ross, 2006).

Furthermore, a number of official bodies have financed exploratory research on corporate manager motivation in the geographic areas under their jurisdiction. Among the most interesting of these studies were those carried out in the United Kingdom and in Australia.

In the United Kingdom, the Health and Safety Executive has been undertaking research in this field for years, both from a qualitative and quantitative perspective (through surveys), specifically in published studies by Michael Wright (1998), Michael Wright and Sara Marsden (2002, 2005), Tony Wright (2000), Haefeli, ${ }^{1}$ Haslam, and Haslam (2005), and Miller ${ }^{2}$ and Haslam (2009). In Australia, the National Occupational Health and Safety Commission commissioned a qualitative study (Gunningham, 1999) and, on the basis of this study, carried out a survey to analyze quantitatively the proposed relationships.

Wright studied the factors that favor prevention management, understood as being either proactive or reactive. Proactive management "implies undertaking actions beforehand, or in the absence of any governmental monitoring action, such as an inspection, prohibition, or warning" (M. Wright, 1998, p. 3). In these cases, one finds that the proactive response varies widely among companies: there are those that comply fully with the law (abide by the letter of the law); those that go beyond the law; those that act in response to demands not required by law; and finally those that act in the absence of external factors. By contrast, reactive management refers to taking action only after receiving warnings, instructions, or sanctions.

In looking for motivating factors, M. Wright distinguishes between intrinsic factors-those depending solely on the organization (cost reduction, ethical considerations, raising morale and productivity, or improving internal organization) - and extrinsic factors related to the organization's surrounding environment, including compliance with legislation (for reasons of principle; fear of sanctions); negative publicity; clients, suppliers, unions, or other pressure group demands; or to avoid eventual litigation.

On the basis of the above definitions, M. Wright has designed a model (Table 1) for analyzing motivation for preventive actions, in which the size of an

TABLE 1. Wright Model (1998)

\begin{tabular}{lcc}
\hline \multirow{2}{*}{ Size } & \multicolumn{2}{c}{ Perception of Risk } \\
\cline { 2 - 3 } Large & Low & High \\
Small & $\begin{array}{c}\text { Moderate } \\
\text { motrinsic } \\
\text { Low intrinsic or } \\
\text { extrinsic } \\
\text { motivation }\end{array}$ & $\begin{array}{c}\text { High intrinsic } \\
\text { motivation }\end{array}$ \\
& & $\begin{array}{c}\text { Moderate } \\
\text { intrinsic } \\
\text { motivation }\end{array}$ \\
\hline
\end{tabular}

Note: Original table based on Wright diagram (1998). 
organization and perceived risk are identified as significant factors. According to this model, company size facilitates extrinsic motivation, and greater perceived risk facilitates intrinsic motivation. There is a positive relationship between size and perceived risk: when both are high, intrinsic factors acquire greater importance. On the other extreme, in small organizations with low perceived risk, both factor types-intrinsic and extrinsic-are less operative. Companies occupy the intermediate points of the model where intrinsic and extrinsic factors operate alternatively and, in a less dramatic fashion, depending on company size and perceived risk. In these relationships, corporate management's experience in major accidents or disasters and knowledge in risk prevention act as positive moderators (toward greater intrinsic motivation), while a poor preventive culture, high costs of preventive measures, and shortage of adequate solutions are negative moderators. Other issues considered in his model are the interactions between motivation and the firm's supply elasticity and/or the firm's demand elasticity, which depend on whether demand or supply is stimulated by clients, suppliers, authorities, circumstances, and experience of major disasters. On the basis of this model, Wright proposed that authorities vary regulatory and promotion measures accordingly (Table 2 ). In the case of regulations, authorities may wish to promote selfregulation (for example, promoting and overseeing implementation of risk prevention management systems) or prescription (defining more concretely the measures to be adopted and overseeing their compliance). Authorities may wish to use persuasive promotion (by way of ongoing dialogue and negotiation) or compulsory promotion (imposing concrete behavioral guidelines). In companies where intrinsic factors play a more significant role, Wright suggests a greater emphasis on

TABLE 2. Wright Model (1998), Proposed Actions

\begin{tabular}{|c|c|c|}
\hline \multirow[b]{2}{*}{ Regulations } & \multicolumn{2}{|c|}{ Prevention Promotion } \\
\hline & Compulsion & Persuasion \\
\hline Self-Regulation & $\begin{array}{l}\text { Moderate } \\
\text { motivation }\end{array}$ & $\begin{array}{l}\text { High intrinsic } \\
\text { motivation }\end{array}$ \\
\hline Prescription & $\begin{array}{l}\text { Low intrinsic or } \\
\text { extrinsic } \\
\text { motivation }\end{array}$ & $\begin{array}{l}\text { Moderate } \\
\text { motivation }\end{array}$ \\
\hline
\end{tabular}

Note: Original table based on Wright diagram (1998). self-regulation and persuasive promotion, while in organizations where both motivating factors are fairly weak, Wright proposes both prescriptive regulations and compulsory promotion.

The work of Gunningham (1999) adds an additional element to the Wright model, which distinguishes the motivation of the executive management of large corporations from the motivation of owners and supervisors of small and medium-sized businesses (SMBs).

According to Gunningham, these two groups are related in that executive managers of large corporations can influence SMB owners and managers through the value chain by requiring certain minimal risk prevention standards from their suppliers and service providers. In both large and small companies, upperlevel management can influence their respective supervisors (middle and lower management) in implementing risk prevention measures. Motivating factors that influence these three groups are the following:

1. Upper Management in Large Corporations and Organizations: The main motivating factors behind prevention are interrelated and include degree of legal responsibility, risk of loss of reputation and credibility, existence of possible personal incentives (mainly economic), possible business/commercial benefits of improved risk prevention management, and the presence and knowledge of prevention management programs.

2. Owners and Managers of Small and MediumSized Businesses: Main motivating factors for risk prevention are legislation, official oversight, supply chain pressure, information, and influence of intermediaries (providers, accountants, insurance companies, auditors, and trade associations).

3. Supervisors: Three factors motivate prevention: training in occupational risk prevention, presence of an evaluation and reward system, and presence of internal disciplinary measures designed to guarantee compliance.

Using this albeit limited, but adequate, theoretical framework, the following questions have been posed:

1. Are these motivating factors applicable in a business context and in Catalonia in particular?

2. Is there a relationship between the importance of each of these factors and company size? 
3. Is there a relationship between the importance of each factor and the position of the interlocutor within the company?

4. Is there a relationship between the importance of each factor and the perceived risk?

Finally, could this information be used to design a motivation strategy adapted to the aforementioned parameters of company size, position in company hierarchy of surveyed person, and perceived risk?

\section{METHODOLOGY}

In an attempt to answer these questions, a series of telephone interviews were conducted with top-level managers and businesspeople in the construction sector. In addition, information was simultaneously gathered from a structured questionnaire (details of fieldwork can be found in Hernández Mateu, 2004).

Sample selection was done among construction companies that were based in Barcelona and were registered in the SABI database (Bureau van Dijk Electronic Publishing) - a total of 2,236 companies at the time the database was queried. Initially, the selection was based on stratified random sampling according to company size. However, because of the low rate of response (around 8\%), sample selection was completed using companies contacted directly through trade associations. The final sample included 198 companies.

In all these companies, the top executive was contacted first, and information on the company's risk prevention policies was requested. In 41 companies, the top executive or manager (owner, president, or general director) provided the information, while the responsibility of providing the information was delegated to other company personnel (61 upperlevel and 96 midlevel managers) in the remaining companies.
With respect to company size, 58 companies $(29.3 \%$ of total) employ between 1 and 10 salaried employees (micro-companies), 81 (40.9\%) employ up to 50 salaried employees (small company), 41 (20.7\%) have up to 250 employees (medium-sized company), and $18(9.1 \%)$ have more than 251 salaried employees.

Each interviewee was asked about safety in his or her company in comparison with competitors (Do you think your company is more or less safe than your competitors?), specific facts about work-related injuries, as well as spot-checks and inspections by the company in the last 12 months. We found that 140 companies (70\% of total) had experienced in the past year 2,306 minor accidents, 38 companies (19.2\%) had had serious accidents, and 4 companies had had fatal accidents. The interview findings by company size are presented in Table 3.

Finally, each interviewee was asked to evaluate his or her behavior/performance in risk prevention (see Table 4, using a 5-point Likert scale (ranging from "strongly agree" to "strongly disagree").

Statistical analysis of data was carried out in three phases. In the first phase, an exploratory factor analysis was done on items included in Table 4 (see, for example, Costello \& Osborne, 2005, for description on using this technique). In the second phase, a two-part confirmatory factor analysis was performed (Jöreskog, 1969), establishing in the first part an unrestricted model, in order to get tests for significance, and in the second part, a simplified model obtained by restricting the significant relationships. The third and final phase was devoted to the analysis of covariates regarding interviewee's position in the company, company size, and the interviewee's perception of safety at his or her company compared with competing firms, using a MIMIC model (Jöreskog \& Goldberger, 1975; Bollen, 1989). In all cases, diagonally weighted least squares estimators were used (Muthén, du Toit, \& Spisic, 1997), together

TABLE 3. Experience of Accidents, Inspections, and Spot-Checks by Technical Officers

\begin{tabular}{lrrrrrr}
\hline & Micro & Small & Medium & Large & Total & Affected \\
\hline Minor Accidents & 45 & 232 & 405 & 1.624 & 2.306 & 140 \\
Serious Accidents & 6 & 9 & 23 & 14 & 52 & 38 \\
Fatal Accident & 0 & 0 & 2 & 2 & 4 & 4 \\
No. of Inspections TSS & 42 & 148 & 242 & 230 & 662 & 129 \\
No. of Spot-Checks CSCS & 19 & 67 & 116 & 61 & 263 & 76 \\
\hline
\end{tabular}

Note: The last column shows number of companies that have experienced each event. 
TABLE 4. Question Regarding Risk Prevention Behavior/Performance: "In general, which of the following statements best describes your risk prevention behavior/performance?"

Item

amesanj

recomit

legisla

masqley

demext

sinpres
Text with Hu and Bentler's (1999) recommended criteria for goodness of fit.

\section{FINDINGS}

Figure 1 shows the Scree diagram of the exploratory factor analysis. In this diagram, one observes a significant level of change between the eigenvalues corresponding to the solution with two and three factors, indicating the appropriateness of the two-factor solution according to Scree criteria. Furthermore, these two eigenvalues, 2.038 and 1.698, are both greater than 1, while the third is less than 1 (0.764), indicating once again the appropriateness the two-factor solution according to Kaiser's criteria.

With regard to the exploratory model results ( $\mathrm{Ta}-$ ble 5, columns 1 and 2, under "Exploratory" heading), larger loadings in the first factor correspond to items amesanj, recommit, and demext elements, allowing one to identify the first factor as extrinsic motivation. In the second factor, by contrast, the greater loadings correspond to items legisla, masqley, sinpres, allowing one to identify this second factor as intrinsic motivation. The adjustment of the model can be considered perfect

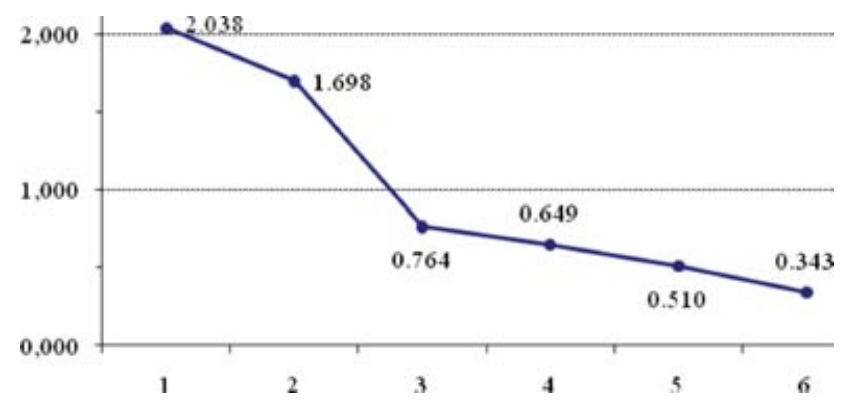

Figure 1 Scree diagram of exploratory factor analysis. according to the chi-squared test, $\chi^{2}(4)=2.907 ; p=$ 0.5731 and the rest of the adjustment indicators.

Performing an unrestricted confirmatory factor analysis requires setting four parameters. The first two parameters are derived from the standardization of both factors, extrinsic and intrinsic motivation, by fixing the variance of each at a value of one. The third parameter is established by setting the loading of the recommit item at zero in the second factor (intrinsic motivation), and the last parameter comes from setting at zero the loading of the sinpres item on the first factor (extrinsic motivation). The only important variations from the exploratory analysis (Table 5, "Unrestricted Confirmatory") are the significant weight of the legisla item on the first factor (extrinsic motivation, with a loading equal to 0.227 ; standard error, $S E=0.073$ ), and that the factors show no significant correlation $(-0.104 ; S E=0.082)$. As in the earlier case, the adjustment indicators show a perfect adjustment: the chisquare test coincides by design with the exploratory analysis, and the remaining indicators are below limit values. The model confirms a structure with two factors and provides standard errors that can be later used for its simplification into a final measuring model.

The final confirmatory factor analysis was done by setting at zero the insignificant relationships obtained in the previous analysis (Table 5, "Confirmatory"). The adjustment indicators again show a perfect adjustment: with a chi-square test, $\chi^{2}(6)=4.444 ; p=0.6167$, and the remaining indicators are once again below their limit values. Furthermore, this model is a restricted version of the earlier model, so one may use Satorra's procedure (2000) to compare both models. The result of the Satorra test is a chi-square test with 4 degrees of freedom, $\chi^{2}(4)=3.002 ; p=0.5569$, indicating that the restrictions do not significantly distort the adjustment of the model. 
TABLE 5. Findings of Measurement Models (phases 1 and 2)

\begin{tabular}{|c|c|c|c|c|c|c|}
\hline \multirow[b]{2}{*}{ Item } & \multicolumn{2}{|c|}{ Exploratory } & \multicolumn{2}{|c|}{ Unrestricted confirmatory } & \multicolumn{2}{|c|}{ Confirmatory } \\
\hline & 1 & 2 & Extrinsic & Intrinsic & Extrinsic & Intrinsic \\
\hline amesanj & 0.686 & -0.046 & $\begin{array}{l}\mathbf{0 . 6 8 5} \\
0.080\end{array}$ & $\begin{array}{r}-0.002 \\
0.071\end{array}$ & $\begin{array}{l}\mathbf{0 . 6 8 8} \\
0.080\end{array}$ & \\
\hline recomit & 0.907 & -0.059 & $\begin{array}{l}\mathbf{0 . 9 0 5} \\
0.097\end{array}$ & $\begin{array}{l}0.000 \\
0.000\end{array}$ & $\begin{array}{l}\mathbf{0 . 8 9 7} \\
0.096\end{array}$ & \\
\hline legisla & 0.177 & 0.455 & $\begin{array}{l}\mathbf{0 . 2 2 7} \\
0.073\end{array}$ & $\begin{array}{l}\mathbf{0 . 4 6 9} \\
0.096\end{array}$ & $\begin{array}{l}\mathbf{0 . 1 8 9} \\
0.066\end{array}$ & $\begin{array}{l}\mathbf{0 . 4 4 0} \\
0.091\end{array}$ \\
\hline masqley & -0.048 & 0.518 & $\begin{array}{l}0.007 \\
0.073\end{array}$ & $\begin{array}{l}\mathbf{0 . 5 1 7} \\
0.086\end{array}$ & & $\begin{array}{l}\mathbf{0 . 5 1 2} \\
0.091\end{array}$ \\
\hline demext & 0.524 & 0.045 & $\begin{array}{l}\mathbf{0 . 5 3 1} \\
0.047\end{array}$ & $\begin{array}{l}0.080 \\
0.073\end{array}$ & $\begin{array}{l}\mathbf{0 . 5 2 8} \\
0.047\end{array}$ & \\
\hline sinpres & -0.091 & 0.847 & $\begin{array}{l}0.000 \\
0.000\end{array}$ & $\begin{array}{l}\mathbf{0 . 8 4 6} \\
0.111\end{array}$ & & $\begin{array}{l}\mathbf{0 . 8 5 8} \\
0.121\end{array}$ \\
\hline $\begin{array}{l}\text { Pro memoria: } \\
\text { Correlation }\end{array}$ & & 0.068 & & $\begin{array}{r}-0.104 \\
0.082\end{array}$ & & \\
\hline $\begin{array}{l}\text { Adjustment } \\
\text { RMSEA } \\
\text { SRMR } \\
\text { WRMR }\end{array}$ & $\chi^{2}(4)$ & $\begin{array}{c}2.907 \\
0.000 \\
0.021 \\
-\end{array}$ & $\chi^{2}(4)$ & $\begin{array}{l}2.907 \\
0.000 \\
0.018 \\
0.318\end{array}$ & $\chi^{2}(6)$ & $\begin{array}{l}4.444 \\
0.000 \\
0.032 \\
0.605\end{array}$ \\
\hline
\end{tabular}

Note: Significant values appear in bold. Standard errors appear in italics.

Finally, the measuring model obtained considers two factors:

1. Extrinsic motivation for risk prevention, which comprise four items: 1) threat of sanction (amesanj), 2) advice and recommendations from inspectors and technicians (recomit), 3) strict adherence to legal provisions (legisla), and 4) acting in response to external demands (demext).

2. Intrinsic motivation for risk prevention, which comprises three items: 1) strict adherence to legal provisions (legisla), 2) acting more rigorously than required by the law (masqley), and 3) acting in absence of external pressure (sinpres).

The two factors, extrinsic and intrinsic motivations, share only one item, strict adherence to legal provisions (legisla) and do not appear to be correlated.

Table 6 shows the findings of the factor analysis with covariates, MIMIC model. One can observe that position in the company hierarchy (position) and perceived risk (risk) are positively and significantly related to extrinsic motivation, while company size (size) is positively and significantly related to intrinsic motivation.
The remaining covariate relationships are insignificant. Covariates predict a $23.6 \%$ variation in extrinsic motivation, and an $18.7 \%$ variation in intrinsic motivation. The adjustment diagnosis is perfect $\chi^{2}(12)=19.012$; $p=0.0882$; RMSEA $=0.063$ and $\mathrm{WRMR}=0.690$. Figure 2 depicts the path diagram, in which only significant trajectories have been drawn for the sake of simplicity.

\section{DISCUSSION}

This article shows that it is possible to analyze methodically the safety motivation of employers. The construct can be assessed by applying a sequence of factor analysis, a well-known method developed by Joreskög, followed by a confirmatory analysis to simplify the resulting measurement. Furthermore, by employing a multiple indicators-multiple causes model, it is possible to study factor correlates with relevant covariates mentioned in previous descriptive works, such as those by M. Wright (in the UK) and Gunningham (in Australia). 
TABLE 6. Multiple Indicators Multiple Causes (MIMIC) Model

\begin{tabular}{|c|c|c|c|c|c|c|c|c|c|}
\hline & \multicolumn{4}{|c|}{ Extrinsic } & \multicolumn{4}{|c|}{ Intrinsic } & \multirow[b]{2}{*}{$R^{2}$} \\
\hline & coeff. & $S E$ & $p$-value & s.coeff & coeff. & $S E$ & $p$-value & s.coeff & \\
\hline \multicolumn{10}{|l|}{ Measurement } \\
\hline recomit & 0.870 & 0.094 & 0.000 & 0.896 & & & & & 0.803 \\
\hline demext & 0.519 & 0.048 & 0.000 & 0.570 & & & & & 0.325 \\
\hline legisla & 0.231 & 0.064 & 0.000 & 0.260 & 0.449 & 0.081 & 0.000 & 0.488 & 0.283 \\
\hline masqley & & & & & 0.522 & 0.088 & 0.000 & 0.561 & 0.315 \\
\hline sinpres & & & & & 0.734 & 0.089 & 0.000 & 0.768 & 0.590 \\
\hline \multicolumn{10}{|l|}{ Covariates } \\
\hline position & 0.585 & 0.175 & 0.001 & 0.435 & -0.020 & 0.189 & 0.917 & -0.015 & \\
\hline size & 0.064 & 0.115 & 0.580 & 0.052 & 0.485 & 0.153 & 0.001 & 0.409 & \\
\hline risk & 0.301 & 0.074 & 0.000 & 0.438 & -0.075 & 0.083 & 0.366 & -0.113 & \\
\hline \multicolumn{10}{|l|}{ Adjustment } \\
\hline Test of model fit & \multirow{2}{*}{\multicolumn{4}{|c|}{$\begin{array}{l}\chi^{2}(12)=19.012 ; p=0.0882 \\
0.063\end{array}$}} & \multirow{2}{*}{\multicolumn{4}{|c|}{$\begin{array}{l}\text { Explained variances } \\
\text { Extrinsic factor }\end{array}$}} & $R^{2}$ \\
\hline RMSEA & & & & & & & & & 0.236 \\
\hline WRMR & \multicolumn{4}{|l|}{0.690} & \multicolumn{4}{|c|}{ Intrinsic factor } & 0.187 \\
\hline
\end{tabular}

Note: Significant values appear in bold.

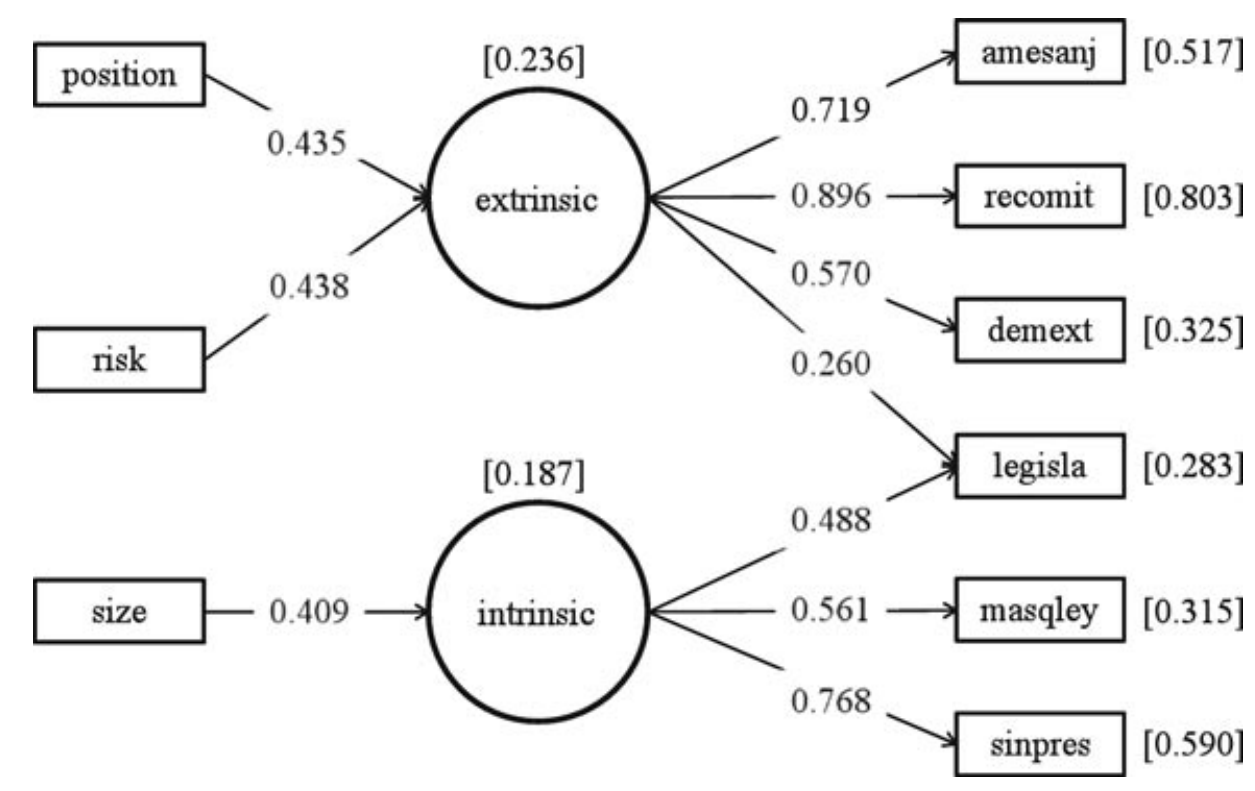

Figure 2 Path diagram-model with covariates.

\subsection{Method of Data Collection}

1. When evaluating the results of this work, keep in mind that the unit of analysis used is "companies" and not "workers." In other words, the results cannot be directly extrapolated to the population of workers. The distribution of companies in most industries and developed countries (even in the United States, according to the Bureau of Labor Business Dynamics Employment Statistics) is highly skewed: while most of the companies ( $85 \%$ and over) are small, roughly half (45\%) of the workers are employed in big companies. 
2. A survey is used as method to collect data. Although surveys are relatively cheap, particularly when using phone or computers to assist in the collection process, consider that the data come from a self-reported study. In the process, every interviewee was assured of the anonymity of the data, and that the data would be used only for research purposes.

3. Many of the results are context sensitive. Some specific issues of this context are 1) that in European countries companies are legally enforced by Council Directive 89/391/EEC on the introduction of measures to encourage improvements in the safety and health of workers at work; 2) that even under the same general legislation, there are different relevant nuances in the transposition or instrumentation of the legislation among countries; and, 3) that all the companies in this study belong to the construction sector. Details on the measurements used are given in the methodology section of this article, to facilitate its use by researchers when analyzing other contexts. The impact of the present context on the results is discussed later.

\subsection{Measurement}

The exploratory factor analysis (see Figure 1, and columns 1 and 2 of Table 5) confirm Wright's work with regard to the existence of two motivating factors for preventive action. Keeping previous research nomenclature, these two factors have been named as extrinsic motivators - related to the environment surrounding the company (surveillance and control system, threat of sanctions, pressure from trade unions, legislation) and intrinsic motivators - that depend on the company or organization (acting beyond the requirements of the law in the absence of governmental or external pressure).

These results agree with those of Wright and can be interpreted similarly, depending on the employer's view on workers' health and safety. On the one hand, the employer may assign an organizational value to occupational risks prevention in terms of improved productivity and worker satisfaction. The employer may take a moral view of the situation (given their nature), which may lead the management to behave ethically to prevent occupational risks (intrinsic motivation). Alternatively, the employer may think that he is only obliged to comply with the law, postponing any consideration to pressure groups closely related to the company's environment, such as unions, clients, or government inspectors (extrinsic motivation).

Further analyses were used to get test results for the parameters (by means of an unrestricted confirmatory analysis, as showed in columns 3 , and 4 of Table 5) and to get a simplified model (using a restricted confirmatory analysis, shown in the last two columns of Table 5). Significant results of these analyses are discussed next.

1. First, the extrinsic and intrinsic motivators were not significantly correlated in our sample, with a value of -0.104 (column 4 of Table 5, and with a ratio estimate/standard error equal to $z=-1.272, p=0.204)$. This result, which departs from previous research, implies that a company that exhibits high external motivation not necessarily will exhibit high intrinsic motivation, and vice versa.

This result is somehow counterintuitive, as intuition could lead one to think that high internal motivation must imply more sensitiveness to external pressures. But this relationship could be contemplated otherwise: a company with high internal motivation to manage occupational risk prevention (ORP) could either shape the way in which its clients or providers manage ORP (through the value chain, as stated by Gunninham); or could get labeled by unions or governmental bodies as a company showing "good preventive practices." For both mechanisms to operate, all that is needed is to find a relationship between intrinsic motivation and company size, as only bigger companies seem able to shape their clients' or providers' way to manage the ORP, and have enough visibility to be labeled as a "good preventive practices" company. This result will be verified when discussing the relationship between external motivation and company size.

2. The double loading of the legislation in both factors. As it is shown in the last two columns of Table 5, the legisla item has significant loadings in both extrinsic motivation (loading $=0.189$, ratio to standard error, $z=2.854, p=0.0043$ ), and intrinsic motivation (loading $=0.440$, ratio to standard error, $z=4.831, p=0.000$ ). These results are to be expected under provisions of the Council Directive 89/391/EEC, 
which requires the employers to systematically manage the ORP (Frick, Langaa, Quinlan, \& Wilthagen, 2003), by implementing the general principles of prevention (Article 2), and stating that the employer shall "aim to improve existing situations" (Article 6), giving support to intrinsic motivation; and remarking the need to take in account workers participation (Article 11), thus supporting extrinsic motivation.

While Wright, when discussing legal issues in the UK, also mentions the need to systematically manage ORP (he qualifies the British regulation as partially mandated self-compliance/goal setting), he doesn't mention the other two sections of the legislation mentioned above, partly because of specific nuances ${ }^{3}$ in the transposition of the directive, and partly because he diminishes the legal argument, given that "the probability of a visit by the HSE is likely to be perceived as too low to have a major influence on site practice. If poor practices are detected the financial or other penalties are insufficient to deter (M. Wright, 1998, p. 82).

In Spain, the improvement of working conditions is explicitly included in the legislation (as in the majority of the European Union Countries), as an obligation not only for the administrative bodies with responsibilities in ORP but also of the companies' participatory committees. And while the probability of an inspection is, generally speaking, "low," receives an extra effort, so in our sample, the expected ${ }^{5}$ yearly rate of having an inspection or spot-check is, for micro-companies $1.1[0.50 ; 2.19]$, for small companies 2.7 [ $2.10 ; 3.35$ ], for medium companies 8.7 [6.32; 12.07], and for large companies 16.2 [6.85; 38.18]. It is also important to note that the visibility of the business prevention activities is high, as one can easily observe many of them from the street (for example, the stability of a scaffold or the protective equipment carried on by the workers). On the other hand, unions' presence is facilitated, even in small construction sites, due to the figure of "zonal delegates" (unions' ORP experts with a geographical adscription) that can activate and impulse participatory mechanisms.

\subsection{Model With Covariates}

Our final model analyzes the impact of three covariates: 1) the position of the interviewee in the company hierarchy (position, a three-level variable), 2) perceived risk ( risk, using a seven-level variable, ranking the perceived incidence of accidents), and 3) company size (size, a four-level variable). One of the relevant findings from this analysis (see Table 6) is that the measurement part of the model fully agrees with that obtained in previous models, in terms of significance and relative strength of the factor loadings. Thus, previous discussion on the details of this structure is fully applicable.

Our most salient results regarding covariate relationships are discussed nextg (numeric coefficients between parentheses are standardized coefficients and $p$-values, as shown in Table 6):

1. Size: As previously observed in studies by Wright (1998) and Gunninham (1999), company size is positively correlated to degree of intrinsic motivation $(S C=0.409 ; p=0.001)$. However, there is not a significant relationship between size and degree of extrinsic motivation $(S C=0.052 ; p=0.064)$.

The significant relationship between size and intrinsic motivation might be explained as in previous research, as a result of the fear of loss of credibility, but, in the construction sector, even in the worst cases, the equity and business risks associated with these accidents is relatively small, and it is also lowers the risk of losing credibility or damaging image. ${ }^{6}$ So, in the context of the present research, this significant relationship could be attributed to the legal dispositions of the European Directive, that have been qualified as better suited for large business (Frick et al., 2003). Indeed, 18 years after the approval of the directive, the Council Resolution on a new community strategy on health and safety at work for 2007-2012 (2007/C 145/01) includes as first area of action for the European countries, to implement "a package of instruments which guarantee a high level of compliance with the legislation, in particular in small and medium enterprises (SMEs) and high-risk sectors," 7 underscoring the inadequacies of the existing legislation regarding SMEs.

The nonsignificant relationship between size and degree of extrinsic motivation is expected, given the significant relationship between size and intrinsic motivation, in the same terms used to discuss the results of the measurement models: both relationships are seemingly the consequence of the two mechanisms described in previous section B. 1 acting together. 
2. Interviewees' position within company hierarchy: position correlates significantly and positively with degree of extrinsic motivation ( $S C$ $=0.435 ; p=0.001$ ). However, there is no significant relationship between position in company and degree of intrinsic motivation $(S C=$ $-0.015 ; p=0.917$ ).

The first relationship, position correlation with extrinsic motivation, could be explained by taking into account that external relationships typically lie among the direct or directly supervised responsibilities of top management and owners, making them more motivated by the external pressures from the value chain, unions, and inspections (and the possibility of prosecution or fines).

Several factors might contribute to the absence of correlation between position and intrinsic motivation. For example, it can be partially explained by taking into account the aforementioned (see previous point 1) lower risk of losing credibility or damaging business image, and hence threatening stakeholder confidence. Additionally, it could also be the result of a lack of commercial benefit from ORP management, as Wright also mentioned for the United Kingdom and Norway, quite opposite to what happens in the United States, where experience rating could make the difference between profit and loses, particularly in the construction industry. Although a financial argument might also play an important role in some European countries (Finland, France, Germany, Italy, and Luxembourg), where there is an adjustment between insurance premiums and cash benefit from the costs issued by mutual insurance companies for workplace accidents and workrelated illnesses. ${ }^{8}$ Such an experience rate system did not exist in Spain, until very recently. ${ }^{9}$

3. Degree of risk perception: risk correlates positively and significantly with degree of extrinsic motivation $(S C=0.438 ; p=0.000)$. However, contrary to Wright, this study finds no significant correlation between perceived risk and degree of intrinsic motivation $(S C=-0.113$; $p=$ 0.366).

As previously mentioned, catastrophic occupational accidents are extremely rare in the construction sector, and hence, there is a low risk of losing credibility or damaging the com- pany's image, and there is also a lack of financial incentive. Since those are the fundamental mechanisms behind intrinsic motivation, the nonsignificant correlation between risk and intrinsic motivation is perhaps not surprising.

In the absence of a direct relationship between risk and intrinsic motivation, risk makes companies more aware of external pressures, as having a serious or fatal accident leads, automatically to one or more inspections. Risk can also more easily be the subject of union complaints, which explains the significant correlation between risk and external motivation.

\subsection{Strategies to Improve Motivation to ORP Management}

Our findings may be useful for designing motivation strategies aimed at these companies to promote intrinsic motivation and to facilitate external motivation. In particular, the following recommendations could be drawn from our results:

1. A greater degree of information and pressure on company owners and directors regarding their responsibilities, for example, through documentation directed at these groups, via third parties (the government, chambers of commerce) and even publicizing legal sanctions. While this strategy directly tries to promote internal motivation, by increasing the possibility of damaging a company's image, it will also facilitate external motivation through the value chain (as client/provider owners and directors will be more sensitive to ORP management) and increasing the fear of sanctions. The first part of this strategy could also be used by an external ORP consultant, directly or indirectly reaching the first line of management.

2. Another possibility is to encourage internal motivation by making a case for the financial argument. This could be directly achieved by introducing experience rate premiums, ${ }^{10}$ so the insurance company would not only guarantee disability coverage for workers but would also promote greater risk prevention on the part of employers (Wright \& Marsden, 2002). This strategy could be implemented also indirectly, trying to show the financial benefits of ORP management; while this kind of 
general approach seems to have been unfruitful, it could be successfully used in specific intervention programs, particularly when those interventions lie in the field of ergonomics, as many of the occupational injuries are related to the musculoskeletal system (for example, the official accident records for 2006 in the construction industry in Catalonia show that $31.5 \%$ of the accidents were overexertion injuries).

3. When strategies addressed to improve intrinsic motivation seem difficult to implement, or simultaneously with those, it is possible to facilitate extrinsic motivation. This seems to be easier to achieve in companies showing a high perception of occupational risks, while in the rest of the companies it seems better to facilitate extrinsic motivation by formal or informal agreements, through the value chain or with worker's representatives (as happens with figures such as local trade union representatives). This kind of approach seems also natural when implementing participatory programs.

Finally, the procedure that we develop in this article could be easily applied and adapted by researchers and technicians working for the government, persons with responsibilities in ORP management, and consultants. Although further research is needed to test the validity of our conclusions to other industries or contexts, every effort will surely result in an improvement of occupational risk management, the health and safety of workers, companies, and the society.

\section{ACKNOWLEDGMENTS}

We are indebted to two anonymous referees for their valuable comments. We acknowledge previous fieldwork done by Mrs. Nuria Hernández Mateu under the supervision of one of the authors.

\section{References}

Ajzen, I. (1991). The theory of planned behaviour. Organizational Behavior and Human Decision Processes, 50, 179-211.

Ajzen, I., \& Fishbein, M. (1980). Understanding attitudes and predicting social behavior. Englewood Cliffs, NJ: Prentice-Hall.

Arco, S. Del, \& Galindo, C. (2006). España tiene un solo inspector por cada 23.300 trabajadores, la mitad que la UE. El País, May 22.
Bird, F. E., \& Germain, G. L. (1986). Practical loss control leadership. Loganville, GA: International Loss Control Institute.

Bollen, K. A. (1989). Structural equations with latent variables. New York: John Wiley \& Sons.

Costello, A. B., \& Osborne, J. (2005). Best practices in exploratory factor analysis: Four recommendations for getting the most from your analysis. Practical Assessment Research \& Evaluation, 10(7).

Dorman, P. (2000). The economics of safety, health, and well-being at work: An overview. Ginebra: International Labour Organisation.

Fishbein, M., \& Ajzen, I. (1975). Belief, attitude, intention, and behavior: An introduction to theory and research. Reading, MA: Addison-Wesley.

Frick, K., Langaa, P., Quinlan, M., \& Wilthagen, T. (Eds.). (2000). Systematic occupational health and safety management. Oxford: Pergamon.

Gil Fisa, A., \& Pujol Senovilla, L. (2000). Metodología para la evaluación económica de los accidentes de trabajo. Prevención, trabajo y salud (7).

Gunningham, N. (1999). CEO and supervisor drivers: Review of literature and current practice. Sydney: National Occupational Health and Safety Commission.

Haefeli, K., Haslam, C., \& Haslam, R. (2005). Perceptions of the cost implications of health and safety failures. Colegate (Norwich): Health and Safety Executive.

Hale, A. R. (2003). Safety management in production. Human Factors and Ergonomics in Manufacturing, 13(3), 185-201.

Hernández Mateu, N. (2004). Identificación de Barreras y Motivadores a la Prevención en la Construcción. Barcelona: Proyecto Fin de Carrera para la obtención del Título de Arquitecto Técnico en la Escuela Politécnica Superior de la Edificación.

Hofmann, D. A., Jacobs, R., \& Landy, F. (1995). High reliability process industries: Individual, micro and macro organizational influences on safety performance. Journal of Safety Research, 26, 131- 149.

Hofmann, D. A., \& Morgeson, F. P. (1999). Safety-related behavior as a social exchange: The role of perceived organizational support and leader-member exchange. Journal of Applied Psychology, 84(2), 286-296.

Hu, L., \& Bentler, P. M. (1999). Cutoff criteria in fit indexes in covariance structure analysis: Conventional criteria versus new alternatives. Structural Equation Modeling, 6(1), 1-55.

Jöreskog, K. G. (1969). A general approach to confirmatory maximum likelihood factor analysis. Psychometrika, 34, 183-202.

Jöreskog, K. G., \& Goldberger, A. S. (1975). Estimation of a model with multiple indicators and multiple causes of a single latent bariable. Journal of the American Statistical Association, 70(351), 631-639. 
Laitinen, H., Marjamäki, M., \& Päivärinta, K. (1999). The validity of the TR safety observation method on building construction. Accident Analysis and Prevention, 31, 463-472.

Miller, P., \& Haslam, C. (2009). Why employers spend money on employee health: Interviews with occupational health and safety professionals from British Industry. Safety Science, 47(2), 163-169.

Muthén, B. O., du Toit, S. H. C., \& Spisic, D. (1997). Robust inference using weighted least squares and quadratic estimating equations in latent variable modeling with categorical and continuous outcomes. Accepted for publication in Psychometrika.

Perrow, C. (1967). A framework for the comparative analysis of organizations. American Sociological Review, 33(2), 194-208.

The Pulitzer Prizes. (2004). The Pulitzer Prize winner. Retrieved May 30, 2006, from http://www.pulitzer.org/ year/2004/public-service/

Reason, J. (1997). Managing the risks of organizational accidents. Aldershot: Ashgate.

Robbins, S. P. (2004). Comportamiento organizacional (J. F. J. D. Martínez, Trans., 10th ed.). México: Pearson Educación cop.

Rundmo, T., \& Hale, A. R. (2003). Managers' attitudes towards safety and accident prevention. Safety Science, $41,557-574$.

Satorra, A. (2000). Scaled and adjusted restricted tests in multi-sample analysis of moment structures. In R. D. H. Heijmans, D. S. G. Pollock, \& A. Satorra (Eds.), Innovations in multivariate statistical analysis. A Festschrift for Heinz Neudecker (pp. 233-247). London: Kluwer Academic Publishers.

Shannon, H. S., Mayr, J., \& Haines, T. (1997). Overview of the relationship between organizational and workplace factors and injury rates. Safety Science, 26, 201217.

Shannon, H. S., Robson, L. S., \& Sale, J. E. M. (2001). Creating safer and healthier workplaces: Role of organizational factors and job characteristics. American Journal of Industrial Medicine, 40, 319-334.

Smallman, C. (2001). The reality of "revitalizing health and safety." Journal of Safety Research, 32, 391439.

Terrés de Ercilla, F., Mondelo, P. R., Álvarez Casado, E., \& Talavera Pedrol, N. (2002). In P. R. Mondelo, W. Karwowski, \& M. Mattila (Eds.), Utilización de modelos causales en el desarrollo de sistemas de gestión de la prevención de riesgos laborales. Ponencia presentada en el congreso ORP 2002, Gran Canaria, 20 a 22 de Febrero de 2002. Paper presented at the Second International Conference on Occupational Risk Prevention (ORP'2002), Gran Canaria, Universitat Politècnica de Catalunya.
Viscusi, W. K. (1986). The impact of occupational health and safety regulation. Rand Journal of Economics, 17(4), 567-580.

Vogel, L. (1998). Controversial incorporation of Framework Directive in Finland. TUTB Newsletter, 10. Brussels: TUTB.

Wallace, B., \& Ross, A. (2006). Beyond human error: Taxonomies and safety science. Boca Raton, FL: CRC Press.

Wright, M. (1998). Factors motivating proactive health and safety management. London: Health and Safety Executive.

Wright, M., \& Marsden, S. (2002). Changing business behaviour-would bearing the true cost of poor health and safety performance make a difference? Colegate, Norwich: Health and Safety Executive.

Wright, M., \& Marsden, S. (2005). A response to the CCA report "Making companies safe: What works?" Colegate, Norwich: Health and Safety Executive.

Wright, T. (2000). IMS - three into one will go!: The advantages of a single integrated quality, health and safety, and environmental management system. Quality Assurance Journal, 4, 137-142.

Zohar, D. (2002). The effects of leadership dimensions, safety climate, and assigned priorities on minor injuries in work groups. Journal of Organizational Behavior, 23, 75-92.

\section{Endnotes}

1. It is important to point out that Hafel et al. have carried out a qualitative study of business owners and managers' perception of costs associated with accidents and work-related illnesses. These authors conclude that economic arguments, at least in Europe, have little weight in managers' motivation for safety and recommend using alternative criteria (similar to those proposed by M. Wright).

2. Miller and Haslam have also done qualitative research on the topic on the basis of in-depth interviews of health and safety professionals in large companies. Their conclusions are similar to those of Hafel and others, although Miller and Haslam see an opportunity to develop the relationship between productivity and workers' well-being.

3. For example, on the specific nuances in the transposition of the directive, those are allowed by the European Law, particularly depending on size and industry. Nevertheless, Vogel (1998) remarks that while in the majority of the European countries their transpositions include the aim to improve existing situations, in a few countries (United Kingdom and Finland), it has been a clause stating that this improvement is 
to be made up to the reasonably practicable (in the United Kingdom) or necessary (in Finland).

4. In Spain, the ratio of the number of workers by inspector rates among the highest of the European Union according to Arco and Galindo (2006), which give a rate of 23,000 workers/inspector for Spain, while the mean of this ratio for the EU countries is 12,000 . The consequent probability of an inspection visit, that according Wright is low in the UK construction industry, can be very high in other countries; for example, in Finland, weekly safety inspections are mandatory by law at every construction site (Laitinen, Marjamäki, \& Päivärinta, 1999).

5. What follows is a naive expectation, given that in Spain it is mandatory by law to make an inspection if a company has suffered a severe or fatal accident (which can trigger several more visits, accompanying police or forensic authorities to determine legal responsibilities). Here bias-corrected inspection rates are computed assuming a Poisson distribution with bootstrapped 95\% confidence intervals (between brackets) and with firm size as a four-level factor.

6. The latter assertion may be because in the construction sector most accidents are individual in nature (Reason, 1997), rather than organizational (as in the case of the nuclear, chemical, and air-transport sectors). When talking only of occupational accidents, the majority of them affect only one worker. and in the case of affecting more than one, two, or a maximum of a small team of workers are affected (we don't have exact data but, in Catalonia in 2006, the official records of injuries suffered by construction workers shows that 13 fatalities correspond to accidents affecting more than one person).

7. Specific actions addressed to SMBs have been undertaken by 14 of the actual 23 European countries that issued health and safety strategies following the Council Resolution, among them Spain and Great Britain (the majority of the other nine are Nordic countries, with a consolidated and efficient treatment of ORP, for example, Finland). Construction lies among the sectors qualified as "high risk" by Council Resolution 2007/C 145/01.

8. These companies are mutual funds that collaborate with the Social Security.

9. A legal disposition was issued on March 2010, establishing premium reductions of up to a $10 \%$, relating them with previous incidence indexes. The bigger part of the burden is externalized to the worker and its relatives, and we do not know any system economically recognizing this burden.

10. Care should be addressed to the exact system (see the previous discussion on this issue), as it seems that systems in which premiums are related to cash benefits are seen as most effective than systems in which premium discounts are related to past indexes of incidence, as has been recently established in Spain (the disposition is very new, so we will have to wait to estimate its real impact). 